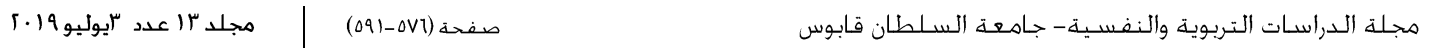
DOI: http://dx.doi.org/10.24200/jeps.vol13iss3pp576-591

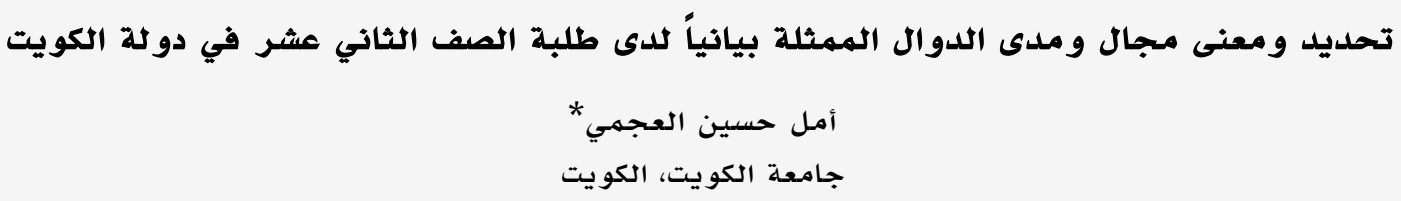

\title{
Twelfth Grade Kuwaiti Students' Identification of Domain and Range in Graphical Representation of Function and the Meaning they Ascribe to them
}

Amal H. Alajmi*

Kuwait University, Kuwait

\begin{abstract}
This research investigated twelfth grade students' performance in identification of domain and range of functions in a graphical representation. The study focused on four types of functions: polynomial, trigonometry, piecewise and discontinuous. The study also aimed to identify the meaning that students gave for the domain and range and how they identified them. To collect the data two instruments were used: a test and an interview. A sample of 216 students participated in the study. The results showed a low performance in identifying domain and range for functions in graphical representation. The T-test indicated a statistical difference in students' performance in domain and range in favor of domain. The results indicated a statistically significant difference in students' performance among the different types of function. Tukey test showed that the difference was in favor of polynomial against the other types of function. Also there was a significant difference between trigonometry and piecewise items in favor of trigonometry. The interviews revealed that students' meaning and common practices in identifying the domain and range reflected misunderstandings. Some of them highlighted that the domain is the $\mathrm{x}$-axis and $\mathrm{y}$-axis or the $\mathrm{x}$-intercept and $\mathrm{y}$-intercept. Others considered that the curve as the domain or the range.
\end{abstract}

Keywords: : Algebra, high school level, function, mathematics, graphical representation.

$\star$ alajmi.a@ku.edu.kw 
و لقد تبين من خلال هذه الدراسـات أن مفهوم

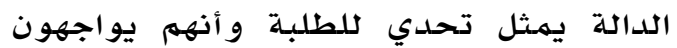
صعوبات متعددة في فهم الدوال و ويرجيع

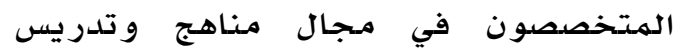

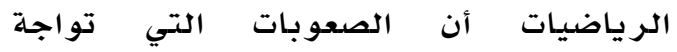

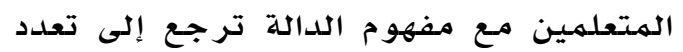
أنواع الدوال مثل كثيرات الحدوود ومتعدددة

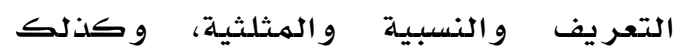
تمثيل الدوال بصور مختلفة مثل الجبرية

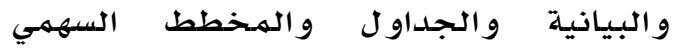
و الموقف الحياتي مما يحتاج معهـ المتعله إلى ادرالك هذه الأنواع و التمثيلات و المهيز الهيزات

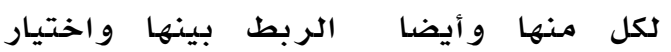
الأنسب منها لحل المشكلات الرياضية (Even, 1998; Knuth, 2000a; NCTM, 2000; Pesek \& Kirshner, 2000; Van Dyke \& White, 2004 )

و نظرا لتعدد أنواع الدوال فيإن الطلبة يواجهون تحديا " في تحديد ما إذا كأ كان إندان

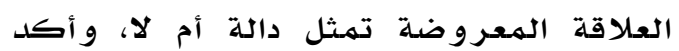
الباحثون أنه يهكن إرجاع الخلل لعدم مقدرة

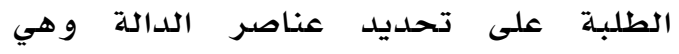

المسجال والمدى والعلاقة بينهـ Bakar, 1991; Van Dyke \& White, 2004) وأيضا يواجه الطلبـة صعوبة في التعامل مـع

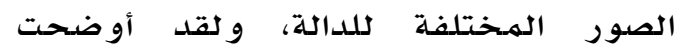

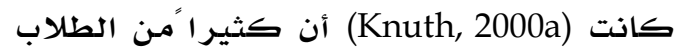
يتجاوز الثانوية وهولا يعي معنى الصور الهور

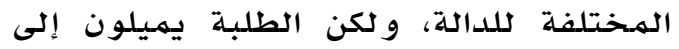

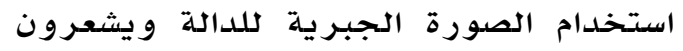
بالثقة أثناء استخدامها والتعامل الموره معها أكثر من الصدور الأخرى، ولقد أرجـع الباحثون

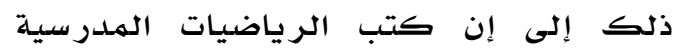
تركز بشكل كبير على الصورة الجبرية

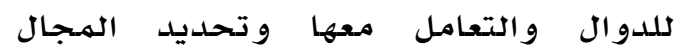

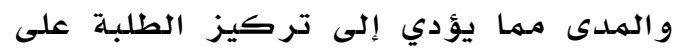

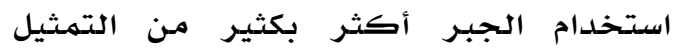

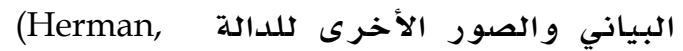
2007; Knuth, 2000b; Van Dyke \& White, 2004)
الدالة مـن المفاهيم الرياضية الرئيسـة في

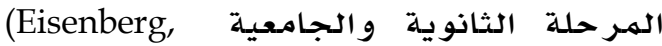
1992;

Kalchman \& Case, 1998). كبيراً من كتب الرياضيات في المرحلة الثانوية و في المـرحلة الجامعية فئإن مفهوم

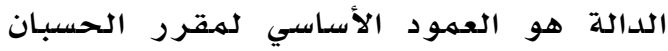

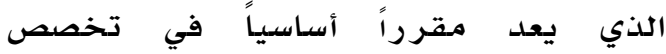

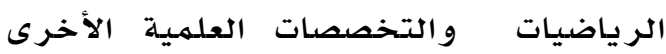

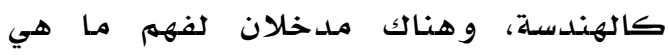

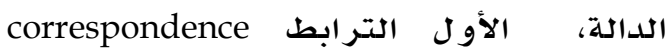

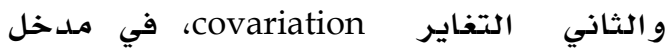

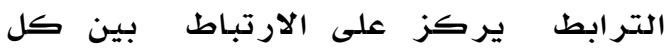
عنصر في س مـع عنصر وحيد في ص، أي أنها تربط بين عناصر الهـجموعتين س و ص من خلال علاقة محددة، وهنا العناصر في لهي المهجموعة ص تابعة للعناصر في المهجموعة

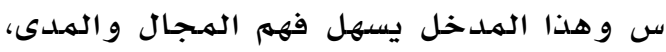
وأيضا إيجاد قوانين للعلاقات بين عناصر س

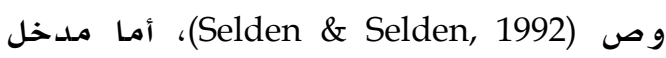
التغاير فيركز على فهم كيف يتغير عنصر في مقابل تغير عنصر أخر، أي كيف تتغير هذه العناصر ككل، فهو يركز على تغير

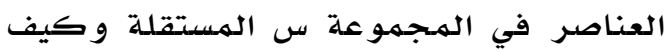

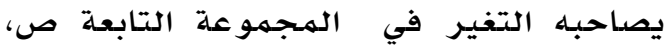

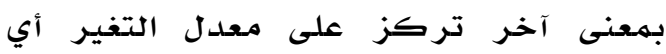
التغير في المجمموعة س مصاحباً بالتغير في المجموعة ص، ووفي هذا التغير يكون تفسيراً

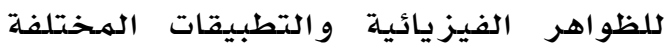

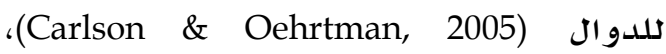
فالمدخل المتباين يساعد على فهم الدالة

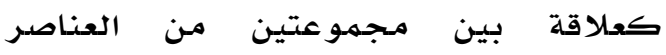

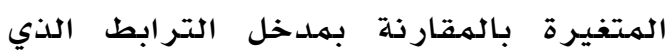

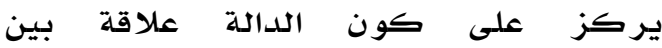

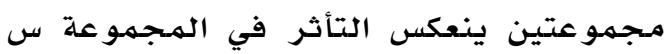
على عناصـر ص، ومدخل التباين هو المدرخل

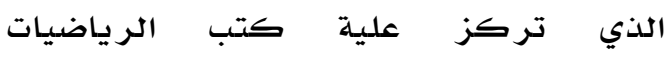
المهدر سيـة.

تناولت الكثير من الدراسات مفهوم الدالة

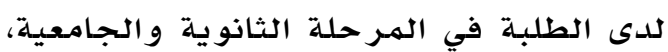


نقاط محور السينات والمدى هو جميع نقاط مدحور الصادات.

(Cho \& Moore-Russo; أجرى شوو مورووسو

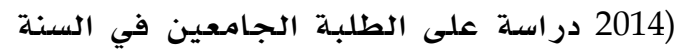

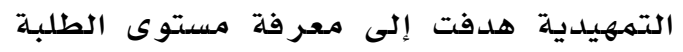

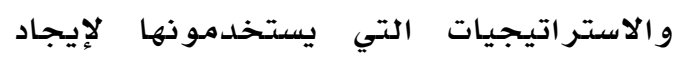

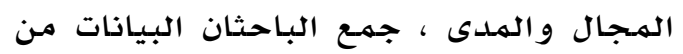

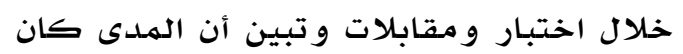
أصعب على هؤلاء الطلبة من المهجال، و أيضا

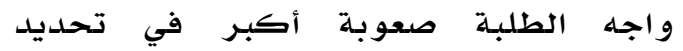

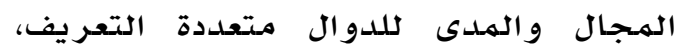
وتبين أن أهم الاستراتيجيات التي استخدمها

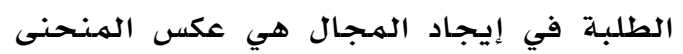

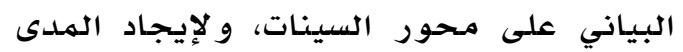

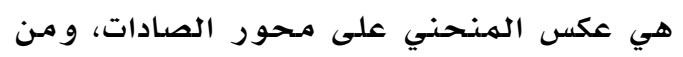

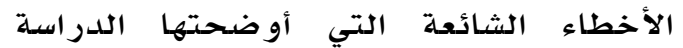

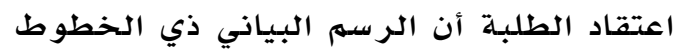

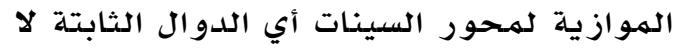

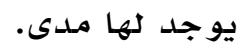

(Cho, أجرى كل من شوونورس موروسو Nراسة Norris \& Moore-Russo; 2017) ركزت على مدى مقدرة طلبـة الجامعة على

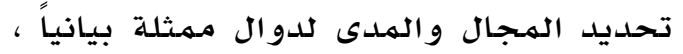

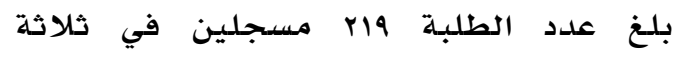
مقررات ، اثنان منها مقررات تمهيدية وهي:

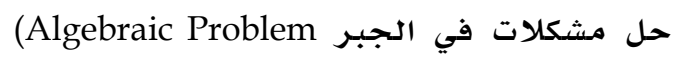
(Pre- وومقرر ما يسبق الحسبـان Solving) Calculus)

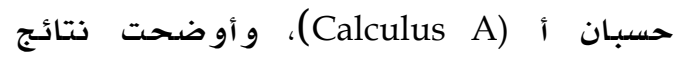
الاختبار أن أداء الطلبة كان بشكل عام

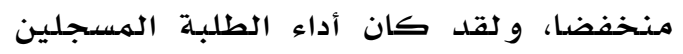
في مقرر حسبـان أ أفضل في تحديد المبجال،

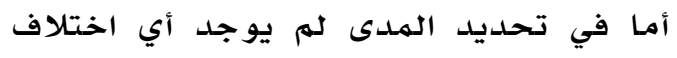

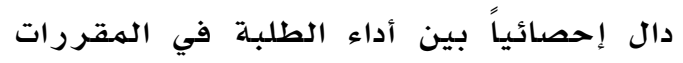

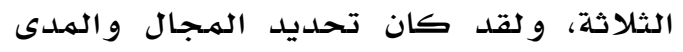

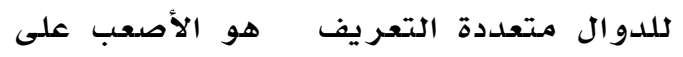

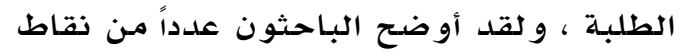

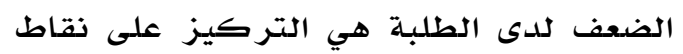

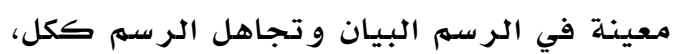
و التركيز على نقاط تقاطع منحنى الدالة
التمثيل البياني يقدم صورة مرئية للدالة

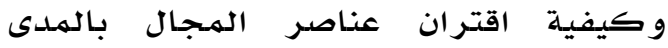
فهويساعد على فهم العلاقة بين المتغيرات في التمثيل البياني واستتنتاج العلاقة بينها والتنبؤ بمسار هذا الرسم البياني، فالتمثيل

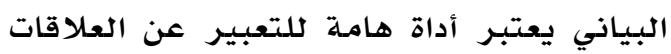

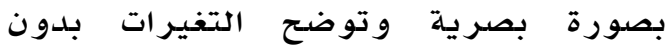
استخدام للكلمات و وعلى الرغم من فو أهمية

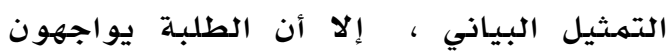

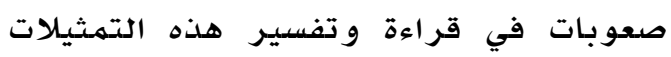

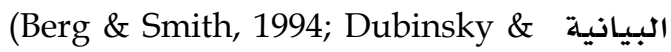
Wilson, 2013; Leinhardt, Zaslavsky \& Stein, 1990)

و على الرغم من أهمية التمثيل البياني

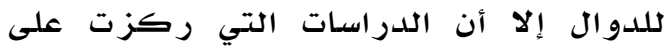
إدراك الطلبة لعناصر الدالة وهي الهـال الهال

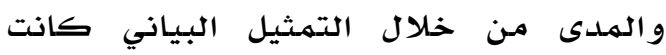

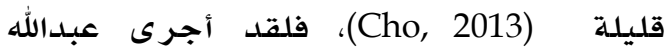
دراسة على طلبة الثانوية (Abdullah, 2010) في ماليزيا ركزت على الدوال و معناها و تحديد نقاط على منحنى الدالة وتبين من فن الدئ

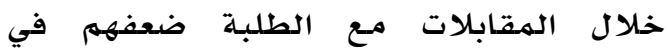

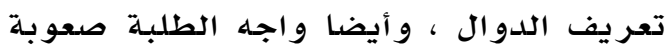

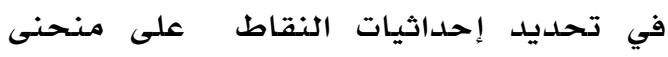
الدالة، فالطلبة بشكل عام لهم يتمكنوا من قر اءة الإحداثي السيني والصورة التي يرتبط لهب

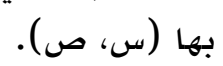

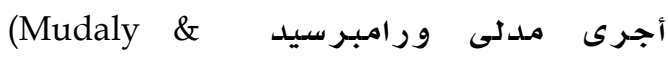
مراسـة لاختبـار مدئل Rampersad, 2010) إدراك طلبة الصف الحادي عشر للتمثيل

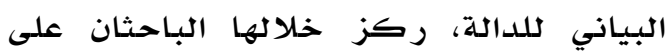
الدوال التربيعية والنسبية و المثلثة و وتبين من خلال المقابلات ضعف مستوى الطلبة في

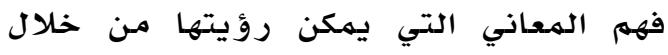

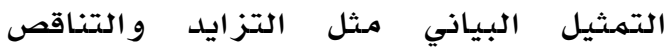

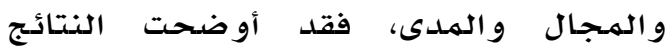
اعتهـاد الطلبة على الحسابات الجبرية لتفسير

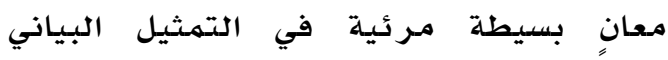
و أيضا اعتقاد الطلبة بأن المسجال هو جميع 
المتعلقة بالدوال المثلثة والربط بين الدوال

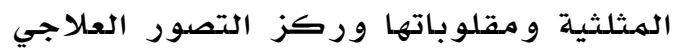

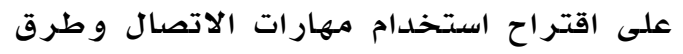
تدريس متنوعة مثل التعلهم التعاوني و أيضا استخدام وسـائل تقويم مختلفة مدئة قام النذير (r.10) بدراسـة على مستوى الطلبة المستجدين في جامعة الملك سعود

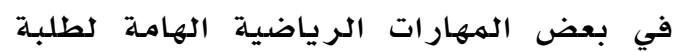

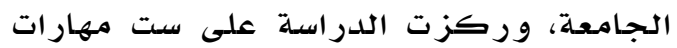

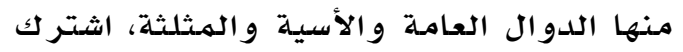

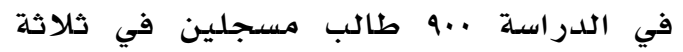
مسار ات: الصحي و العلمي و الهندسـة، استخدم

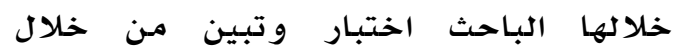
النتائج ضعف مستوى الطلبة في لونميع المهارات بما فيها الدوال العامـة والأسية

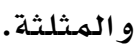

تبين من خلال استعراض الدراسـات السـابقة قلة الدراسـات التي تناولت الدوال في الدوطن العربي في مجال الدوال وأن الدراسـات التي

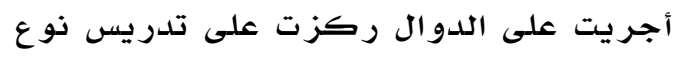
معين من الدوال مثل الدوال الحقيقية في

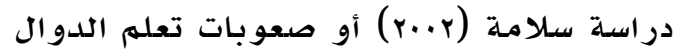

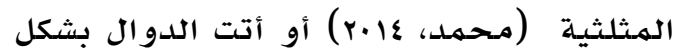

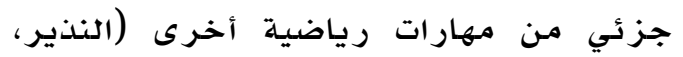

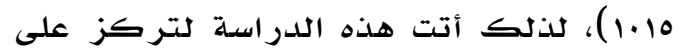
التمثيل البياني للدوال و مدلى إدراك الطلبـة

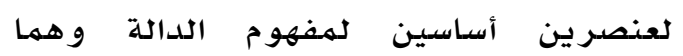
المجال والمدى للدوال في تمثيلها البياني، و لقد شملت الدرراسة على الدوال التي تركز عليها الكتب المدررسية في دولة الكويت، حيث أن كتب الرياضيات المدرسية في الكويت تبدأ بالدوال كثيرات الحلدود من الهرحلة الهريات المتوسطة وتتوسع فيها في المـرحلة الثانوية

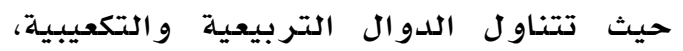
و الدوال المثلثية في الصف العاشر، و الدووال متعددة التعريف و وغير المتصلة فتبدأ مـع

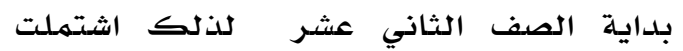

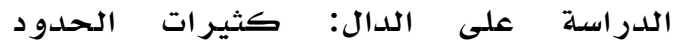
و المثلثية و متعددة التعر يف و غير الهتصلية.
مـع محور السينات أو الصادات، والخلط بين

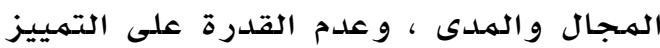

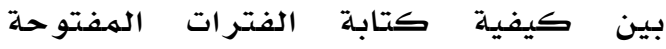

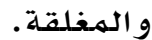

(Aziz \& Kurniasih, أجرى عزيز وكرنيش

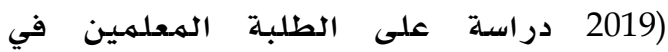
برنامـج الثانوي في إندونيسيا وشاركي

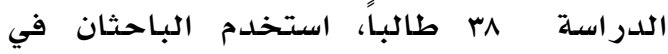

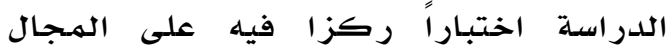
و المدى للدوال عرضت في صور متعددة منها بياني وجبري و ومخطط سهمي، تبين من النتائج عدم مقدرة هؤلاء الطلبة المعلمين على تعريف المجال و المدى بشكل صديح وضعفهم في فهم المـجال والمدى للدوال في صور ها المختلفة، وضعف قدر تهمم على إيجاد

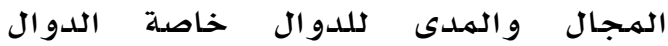
المثلثية.

و في الوطن العربي أجريت القليل من فن

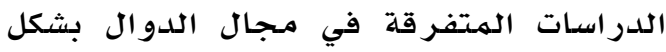

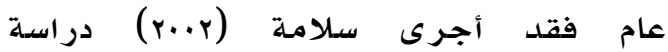
تجريبية هدفت إلى معرفة تأثير المدخل

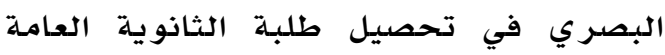
للدوال الحقيقة وخفض القلق الرياضي،

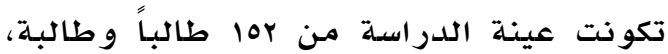
وضع الطلبة في مجسمو عتين: التجريبية و الضـابطة، وتبين مـن خلال الدراسـة تأثير النهموذج البصري في تحصيل الطلبـة وخفض القلق الرياضي لديهم.

و أجرى كذلك محمد (عا.ب) دراسـة هدفت لهعرفة الصعوبات التي تواجه طلبة الصف

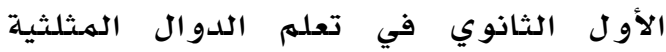

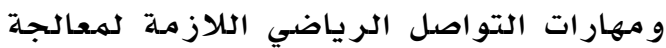
هذه الصعوبات، اشتملت عينـة الدراسة على بر من معلهي و موجهي الرياضيات و و.1 من

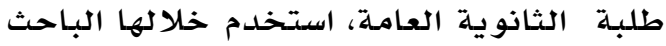
استبانات ومقابلات طبقت على موجهي

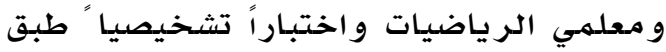
على الطلبسة، تبين من خلال النتائج وجئ

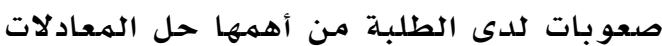




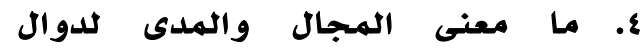
رياضية ممثلة بيانياً من وجهة والمهال نظر طلبة الصف الثاني عشر مئه

๑. كيف يحدد طلبة الصف الثاني عشر المجال والمدى للدوال رياضية ممثلة بيانيأ

أهداف الدراسلة

مفهوم الدوال من الهفاهيم الهامهة في

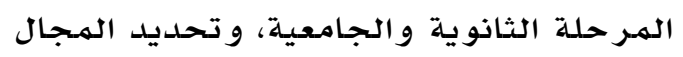

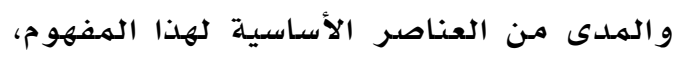

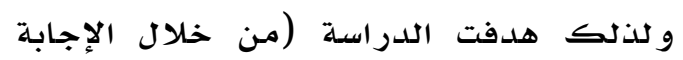

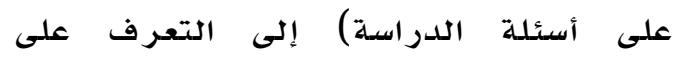

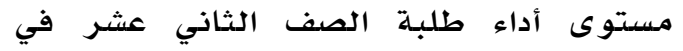
إيجاد المـجال و المدى لدول ادواءل ممثلدة بيانيا ومعني المسجال و والمدى لديهم وكيفية تحديدها على الرسم البياني للوقوف على الدي الأخطاء التي يمكن أن يقعوا فيها عند تحديد الديد

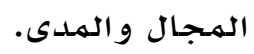

أهمية الدراسة

يستمد البحث أهميته مـن أهمية مفهوم الدالة في الرياضيات و العلوم الأخرى ، فمفهوم

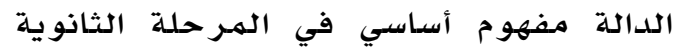
والجامعية فهو هدف هام من أهداف تعليم

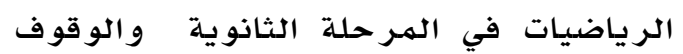
على مستوى أداء الطلبـة في إيجاد المـجال

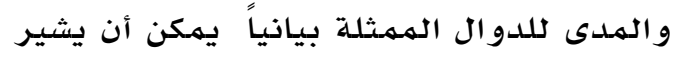
إلى وجود قوة أو خلل في مستوى الطلبة

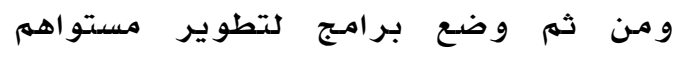

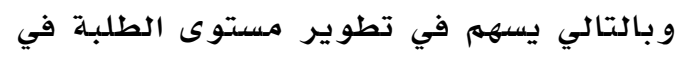

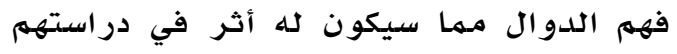

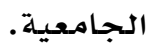

إثر اء البحث في مجال الدوال حيث تبين من

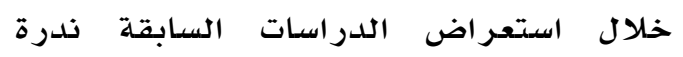
الأبحاث التي أجريت في هذا الهـال في الدال

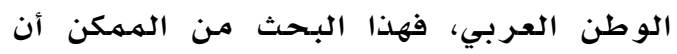

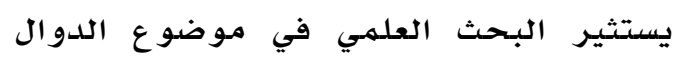
و يدفع إلى إجر اء دراسات متعددة فيه.
مشكلة الدراسة

على الرغم مـ أهمية مفهوم الدوال الرياضية في المـرحلة الثاذوية و والجامعية (Even, 1998; Knuth, 2000a) خبرة الباحثة فقد لاحظت وجود شكاوى من

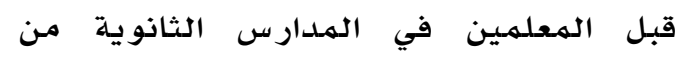

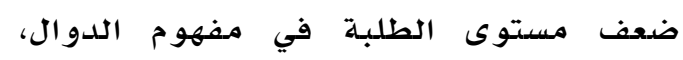

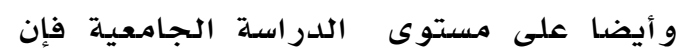

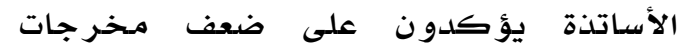

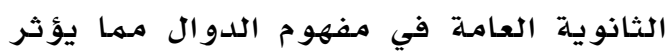

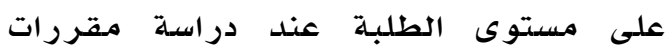

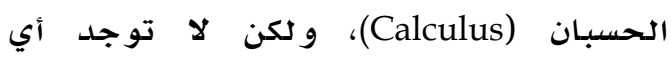
دراسات على مستوى دولة الكويت في مفهوم الدوال لدى الطلبهة، لذلك فإن رصدي مستوى

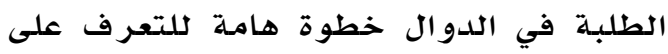

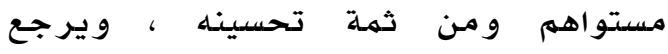
الباحثون ضعف الطلبة في مفهوم الدوال إلى منى عدم إدراك عناصر الدالة الأساسية وهي مهولي الهجال والهدى (Tall \& Bakar, 1991; Van Dyke \& White , 2004)

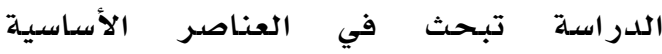

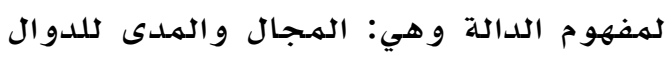
الممثثلة بيانيا من خلاهو

$$
\text { أسئلة الدراسة }
$$

1. ما مستوى أداء طلبة الصف الثاني

عشر في دولة الكويت في تحديد المجال والمدى لدوال رياضية ممثلة بيانيأ

r. ما دلالة الفروق في مستوى أداء طلبة الصف الثاني مشر في تحديد كل من المجال والمدى لدوال رياضية ممثلة بيانيأ

r. ما دلالة الفروق في مستوى أداء طلبة الصف الثاني عشر في تحديد المجال والمدى لدوال رياضية ممثلة

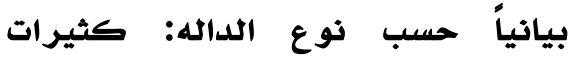
الحدود ومتعددة التعريف والمثلثية

وغير المتصلة؟ ودهو 
مدرسلة للبنات وأخرى للبنين بطريقة

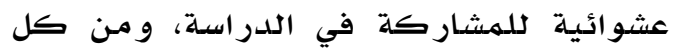
مدرسة من هذه المدارس تمّ اختيار فصلين

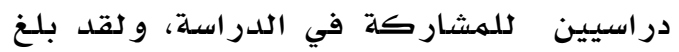

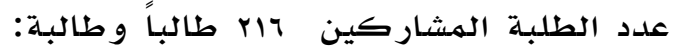

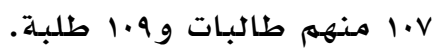

أدوات الدراسة

استخدمت الباحثة أداتين لجمـع البيانات

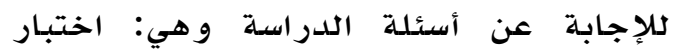
و مقابلة. الاختبار

\section{أولاً : إعداد الاختبار في صورته الأولية} تم" تصميم الاختبار لجمـع البيانات اللازمة

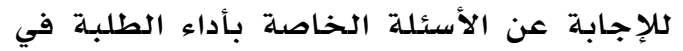

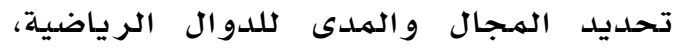
و الاختبار مـن النوع الموضوعي حيث وضعت الرسهم البياني للدانة وتلا كل كل رسو رسم بياني

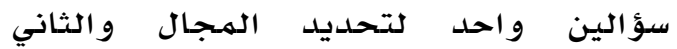
لتحديد المدى و لكل سؤال خمس ولدس اختيارات يحدد من بينها الطالب الإجابة الصحيحلة ولهدل ثانياً : التحقق من صدق الاختبار بعد تصميهم الاختبار تهّ عرضه في صدورته

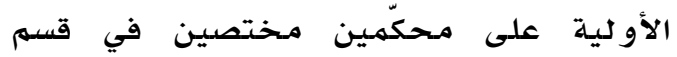
الرياضيات بكلية العلوم جامعة الكويت، و وتم توضيح الهدف مـ الاختبار، والهستوى

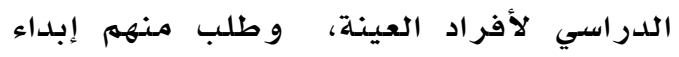

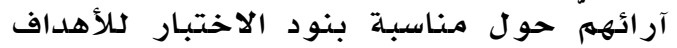
التي وضـع من أجلها ، و مدى منـاسبـة بنود

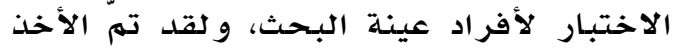

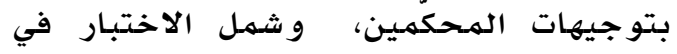
صورية النهائية، على أربعة رسوم بيانية لكل

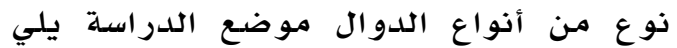

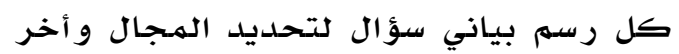
للمدى، أي أن مجمموع البنود بr بـ بند، شكل 1 أحد التمثيلات البيانية الواردة في الاختبار.
حلدود الدراسـة: تتحدّد نتائج الدراسـة بما يلي:

حدود موضوعية: اقتصرت الدراسـة على

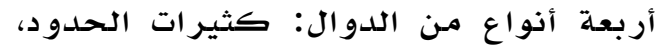
و متعددة التعريف، و الهثلثية، و غير المتصلية. حدود بشرية: اقتصرت الدراسـة على الطلبة الكويتيين في الصف الثاني عشر مـن القسهم العلهي في المدارس الحكومية. مصطلحات الدراسة

الدالة: هي علاقة بين مجموعتين حيث يرتبط كل عنصر في المجسموعة الأولى

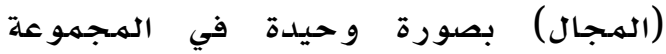
الثانية (الهـجال الهقابل).

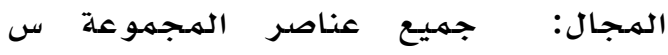
(العناصر المستقلة) التي تكون الدالة معرفة عليها ، أي أنها تحقق الدالة، وفي التمثيل البياني للدالة يكون المهال جميع إحداثيات الهـات

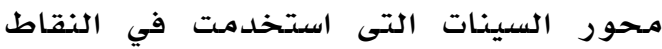

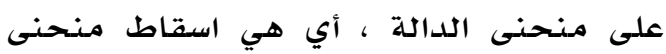

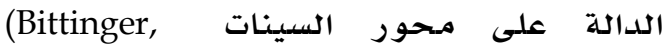
Ellenbogen, \& Johnson, 2010, p.245) المدى: هوجميع صور عناصر المجال

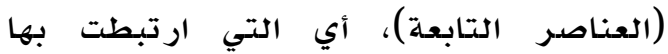

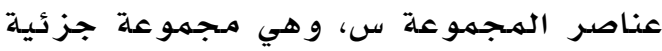

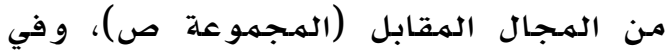
التهثيل البياني للدالة يكون الهـدى جميع

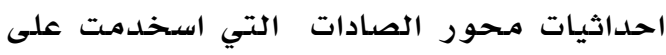
منحنى الدالة، أي هو اسقاط منحنى الدالة الدي

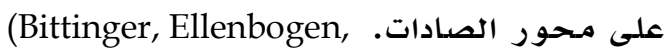
\& Johnson, 2010, p.245)

\section{إجراءات الدراسة}

\section{مجتمع الدراسة وعينتها}

تكوّن مجتمهـع الدراسـة من طلبـة الصف الثاني

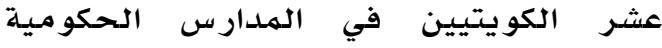

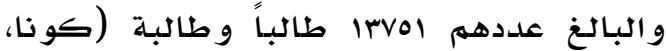

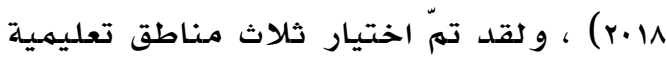

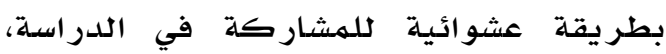
وومن هذه المناطق التعليمية تم اختيار 
حيث احتوى هذا المحور على تمثيل بياني للدوال وطلب من الطلبة تحديد المجال باللون الأحمر و المدى باللون الأخضر.

ثانياً: التحقق من صدق المقابلة بعد تصميم المقابلة تمّ عرضها في صور تها الأولية على محكمين مختصين في قسم الرياضيات بكلية العلوم بجامعة الكولئ الكويت،

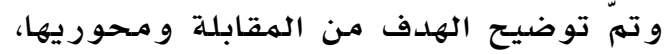

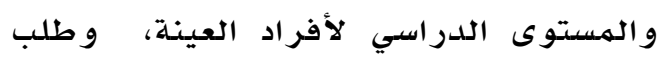

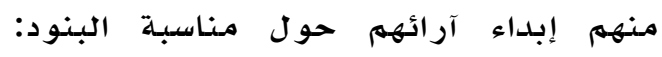
للمحاور و للأهداف التي وضهم التهم من أجلها

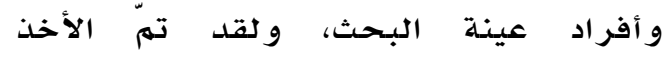

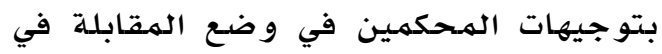

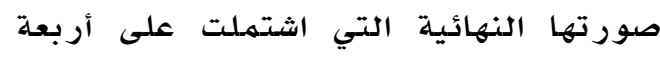

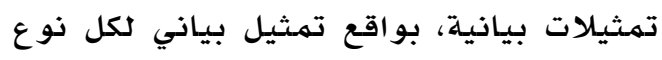

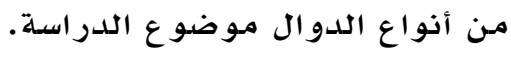
ثالثاً: تجريب المقابلة استطلاعياً ويهدف هذا التطبيق الاستطلاعي إلى

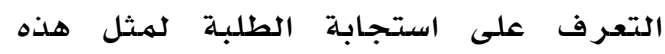

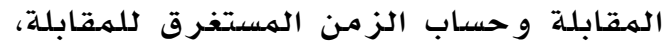

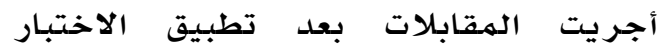

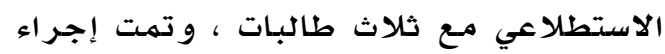
المقابلات بواسطة الباحثة، ولقد تمر توضيح

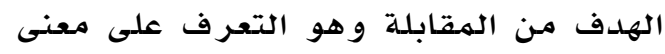

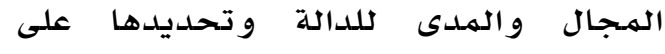

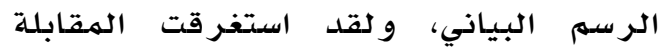
الواحدة حوالي 10 دقيقة. تطبيق أدوات الدراسة

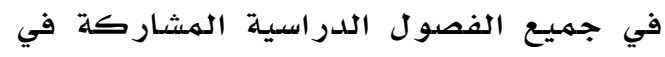

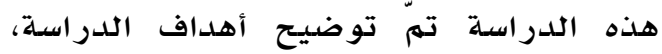

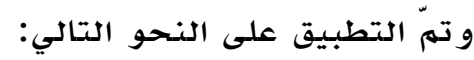

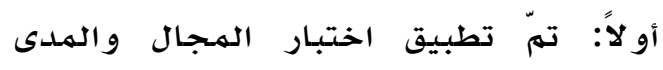

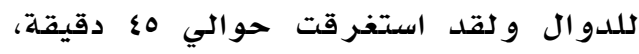

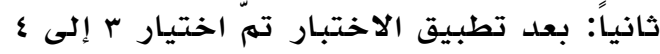
من الطلبة من كل فصل بطريقة عشوائية،

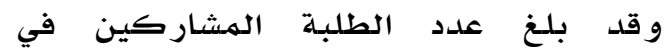
المقابلة 19 طالباً و و طالبة طالبة أي اء طالباً

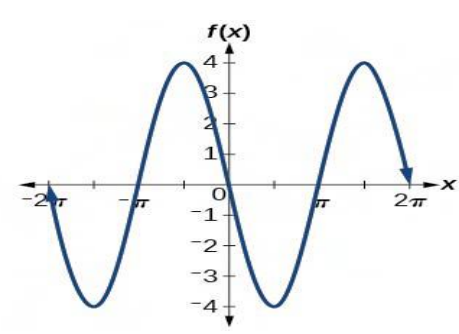
r) مدى الداله هو
a) $(-\infty, \infty)$
c) $\{-2 \pi, 2 \pi\}$
d) $(-2 \pi, 2 \pi)$

b) $[-4,4]$

e) $[0,4]$

1) المجال للداله هو

a) $(-\infty, \infty)$

b) $[-4,4]$

c) $\{-2 \pi, 2 \pi\}$

d) $(-2 \pi, 2 \pi)$

e) $[0,4]$

\section{شكل 1}

أحد بنود الاختبار للاوال المثلثية

ثالثاً : تجريب الاختبار استطلاعياً

و يهدف هذا التطبيق الاستطلاعي إلى حساب

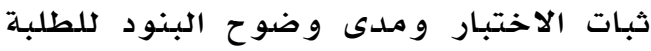
والوقت الدلازم لأداء الاختبار . قامت الباحثة البادية بتطبيق الاختبار على عينة استطلاعية

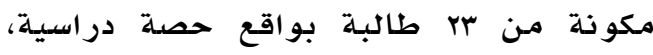
و تبين من خلال التطبيق أن بنود الاختبار

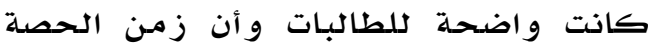

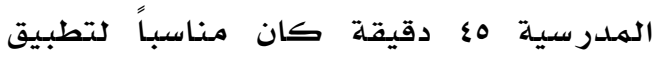

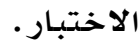

تم" حساب ثبات الاختبار بطريقة إعادة الاختبار (Test retest)، فقد تم حساب التاب نتائج

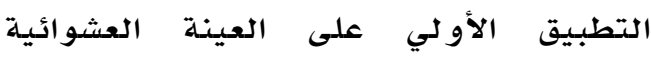

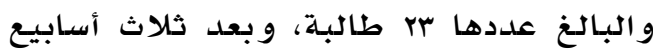

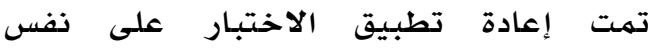

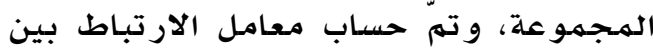

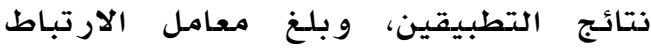

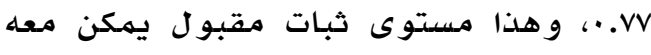
تطبيق الاختبار.

المقابلة أولاً: إعداد المقابلة احتوت المقابلة على محورين الأول معنى

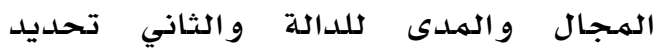
المجال والمدى على التمثيل البياني للدالة 
المركزية تمبركز درجات الطلبة حول حول

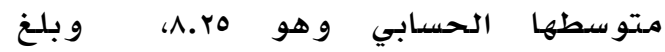

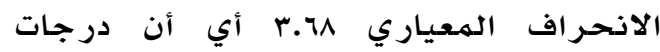

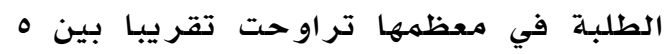

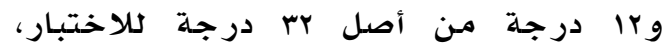

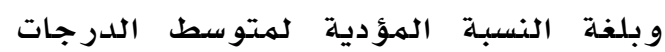
\%ro.V

و لقد بلغ معامل الالتواء ب.1 أكبر من ا مهما يدل على أن توزيع مجمهوع درجات الطلبة

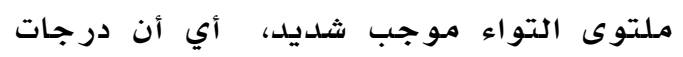
الطلبة كانت في جهة المنتخفضلة. الإجابة عن السؤال الثاني نص السؤال الثاني على: "ما دلالة الفروق في مستوى أداء طلبة الصف الثاني عشر في

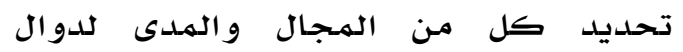
رياضية ممثلة بيانياً ؟" تكون الهجال اختبار الدوال

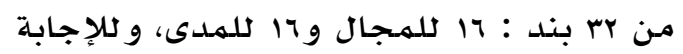

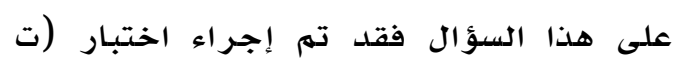

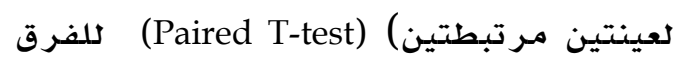
بين أداء الطلبـة في للبنود المخرصص للمسجرال

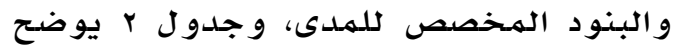
متوسط الدرجات والانحر اف الهعياري وبيان الفروق ودلالتها الإحصائية بين أداء الطلبة

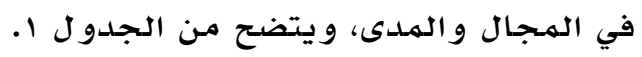

و طالبـة، ولقد استغرقت المقابلة الواحدة حوالي 10 دقيقة. المعالجات الإحصائية

تمَّ استخدام التحليل الكمي و الكيفي للإجابية

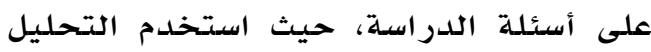
الكمي لإِجابة على الأسئلة المتعلقة بأداء

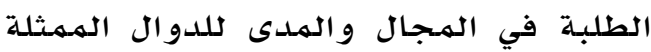

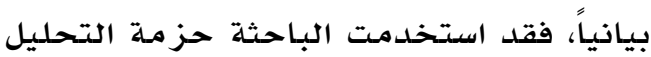

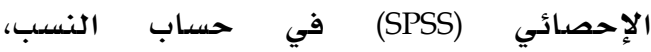

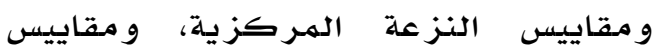
التشتت و واختبار ت ت T-test و فاء

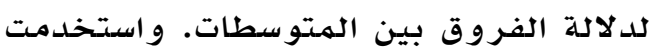
الباحثة التحليل الكيفي للإجابية على السؤال

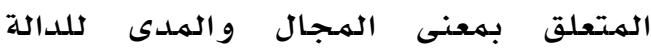
ووكيفية تحديدها على الرسهم البياني

\section{نتائج الدراسة}

الإجابة عن السؤال الأول

نص السؤال الأول على: "مـا مستوى أداء طلبة الصف الثاني عشر في دولة الكويت

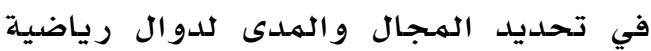
ممثثلة بيانياًء" و للإجابة عن هذابل هذا السؤال فقد الهد

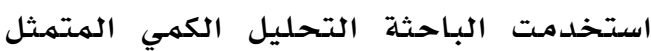

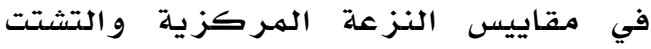

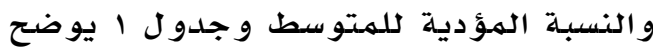

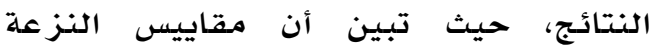

جدول 1

مقاييس النزعة المركزية والتثتت والنسبة المؤية لمتوسط أداء الطلبة في الاختبار

\begin{tabular}{|c|c|c|c|c|c|c|}
\hline \multicolumn{2}{|c|}{ مقايييس التشتت } & \multirow{2}{*}{ النسبة المؤية لمتوسط } & \multicolumn{3}{|c|}{ مقاييس النزعة المركزية } & \multirow{2}{*}{ للاختبار } \\
\hline المدى ل الم ل & الاتحراف المعياري & & منوال & وسيط & متوسط & \\
\hline YA & r.T人 & ro.V & v & $\wedge$ & A.ro & rY \\
\hline
\end{tabular}

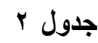

متوسط الارجات والانحراف المعياري وبيان الفروق ودلالتها الإحصائية بين أداء الطلبة في البنود المخصصة للمجال والبنود المخصص للمدى

\begin{tabular}{|c|c|c|c|c|c|c|c|c|}
\hline \multirow[t]{2}{*}{ مسنتى الدلالة } & \multirow[t]{2}{*}{ قيمة ت } & درجات & الانحراف & أقل درجة & أعلى & منوسط الدرجات & عدد & 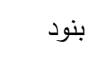 \\
\hline & & الحرية & المعياري & & درجة & & الطلبة & الاختبار \\
\hline \multirow[t]{2}{*}{$\ldots{ }^{*}$} & $0 . r \Lambda$ & r1o & r.rA & . & $1 \varepsilon$ & 纟.7. & Y17 & المجال \\
\hline & & & Y.l. & . & $1 \varepsilon$ & r.70 & $Y 17$ & المدى \\
\hline
\end{tabular}


الدوال كثيرات الحدود على الترتيب البنود المتعلقة بالدوال المثلثية ثمر الدوال غئ غير

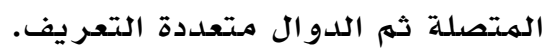

مثوسط درجات الطلبة حسب نوع الدالة

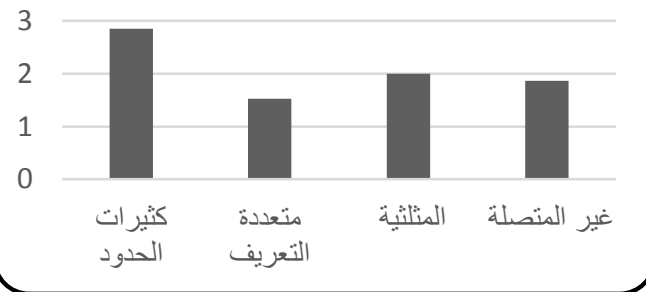

شكل r

متوسط درجات الطلبة حسب نوع الدالة

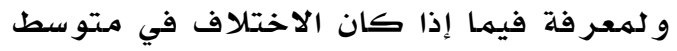

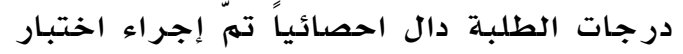

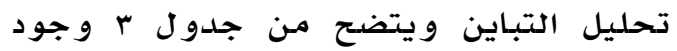

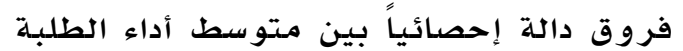

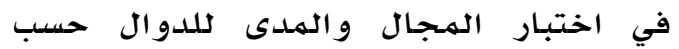

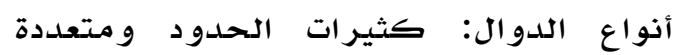

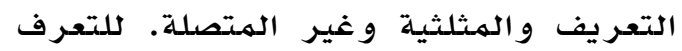

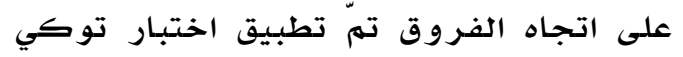

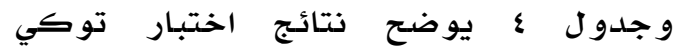
للمقار نات البعدية للفرق بين متوسطات أداء

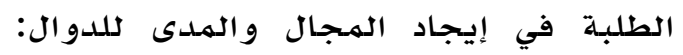
كثير ات الحلدو د و متعددة التعريف وله والهثلثية
و جود فرق ذي دلالة إحصائية عند مستوى •.. بين أداء الطلبـة في بنود الهـجال وبنود المدى لصدالح البنود المخصص للمهجال، فقد ادله كان متوسط درجات الطلبـة في البنود

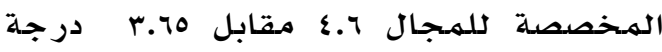
للبنود المخصص للمهدى. الإجابة عن السؤال الثالث

نص السؤال الثالث على: "مـا دلادة الفروق في مستوى أداء طلبة الصف الثاني عشر في تحديد المـجال والمدلى لدوال رياضيلة مـثثلة

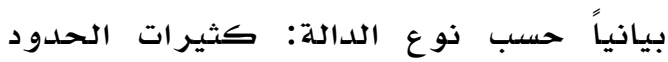

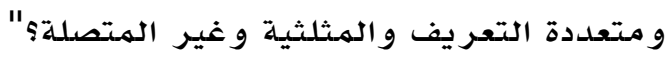
احتوى اختبار الدوال على بr بـ بند، ثمانية بنود لكل نوع من أذواع الدوال: كثيرات

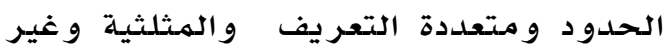

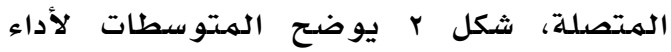

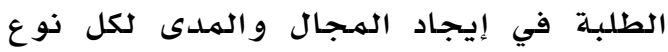
من هذه الدوال، ويتضح أن أداء الطلبـة في

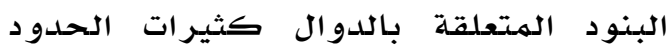
كان الأعلى، و على الرغم من أن أداء الطلبـة

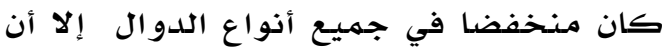

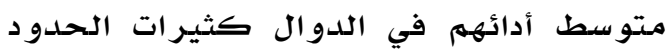

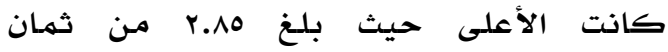
درجات، أي تقريبا ثلث الدرجة تقريبا، يلي يلي

\section{جدول r}

نتائج تحليل التباين لالالة الفروق في أداء الطلبة في اختبار المجال والمدى حسب أنواع الدوال : كثيرات الحدود ومتعدة التعريف والمثلثية وغير المتصلة

\begin{tabular}{|c|c|c|c|c|c|}
\hline مستوى الدلاله & قيمة ف & منوسط المربعات & درجات الحرية & مجموع المربعات & مصدر التباين \\
\hline \multirow[t]{5}{*}{$\cdots \cdots$} & $\varepsilon 1 . \leqslant \wedge$ & 71.91 & r & Y.T.VE & بين المجموعات \\
\hline & & & $\wedge 7$. & 1A. r.vo & داخل المجموعات \\
\hline & & & Y10 & VTו.To & بين الأفراد \\
\hline & & 1.77 & $7 \leq 0$ & 1.81 .01 & الخطأ \\
\hline & & & אוד & $r \ldots 9 . \leqslant 99$ & المجموع \\
\hline
\end{tabular}

دول

نتائج توكي لمقارنات الفروق بين متوسطات أداء الطلبة في تحديد المجال والمدى للدوال: كثيرات الحدود ومتعددة التعريف وإلمثلثية وغير

\begin{tabular}{|c|c|c|c|c|}
\hline \multicolumn{5}{|c|}{ المتصلة } \\
\hline غير المتصلة & المتلثية & متعددة التعريف & كثيرات الحدود & أنواع الدوال \\
\hline$* .99$ & $* . \wedge 7$ & r. & & كثيرات الحدود \\
\hline .r. & $\because \cdot . \Sigma V-$ & & - Tr. & متعددة التعريف \\
\hline. $.1 T$ & & $\because$ * . $\leqslant V$ & * $\cdot . \wedge T-$ & المثلثية \\
\hline & $. .1 r-$ & $. r \leq-$ & $* . .99-$ & غير المتصلة \\
\hline
\end{tabular}


تحديد المدى بنقاط تقاطع المنحنى مع المعادات مدحور الصادات.

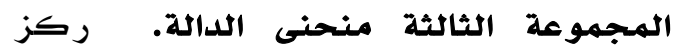

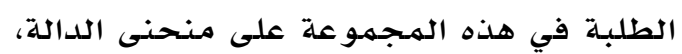

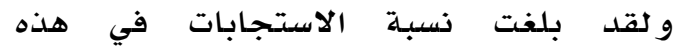

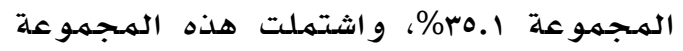

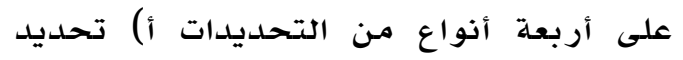

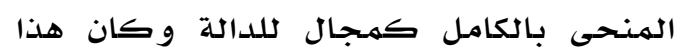
التحديد هو الأكثر شيوعا بين الطلبـة، بال)

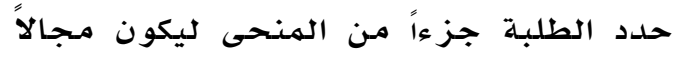

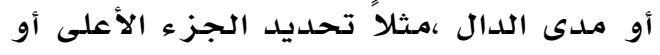

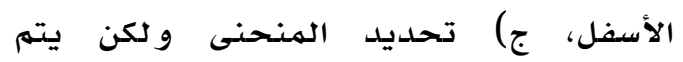

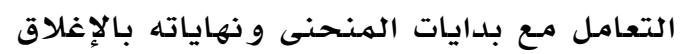

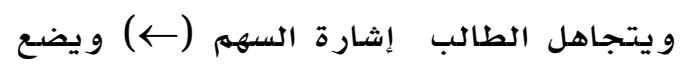
بدل منها نقطة أو يتجاهل الدائرة المفتوحة التهارة

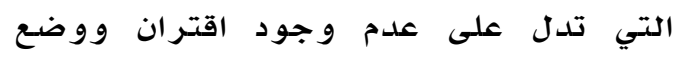
نقطة (شكل r).

المجموعة الرابعة المساحات. ظلَّ الطلبة في هذه الهجمهوعة مساحة من الرسم البياني

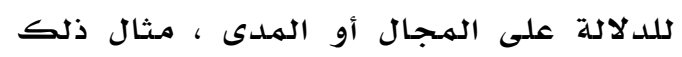
تظليل الهساحة أعلى الهنحنى أو أسفل منهـ. المجموعة الخامسة لا يوجد مدى. أنكر أربع من الطلبة وجود مدى للدالة غير الهتصلية. المجموعة السادسة لا نعلم. كانت استجابات الطلبة في هذه الهمجموعة الأعلى وبلغت

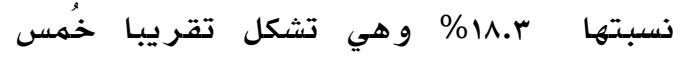
استجابات الطلبة.
و لكن في هذا الرسهم البياني أدى إلى تحديد

سليهم شكل r.

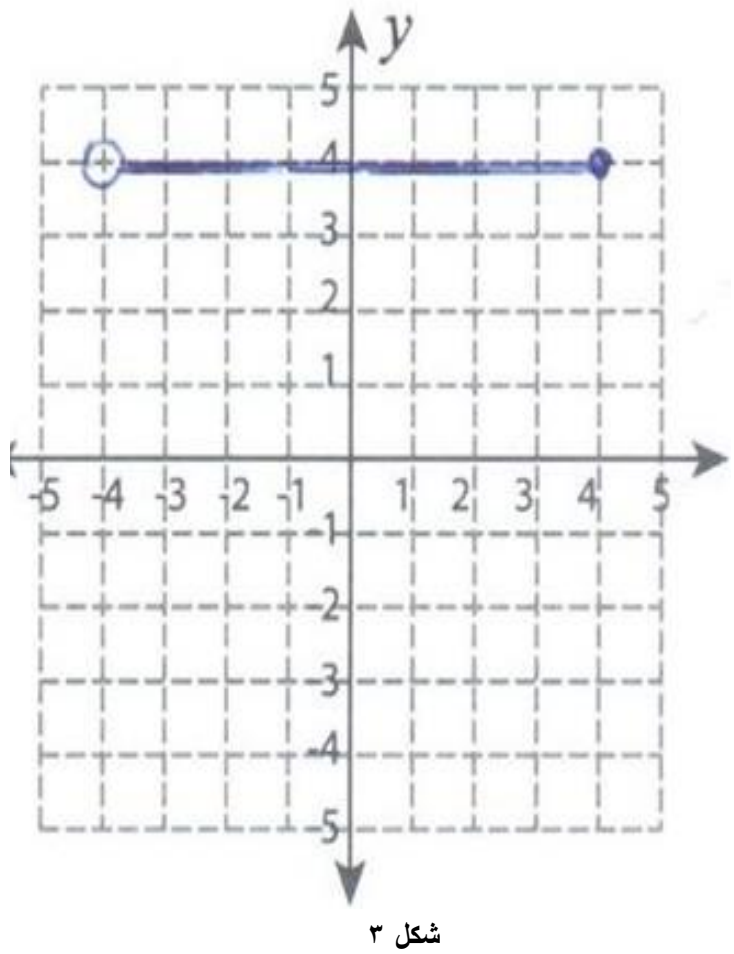

بند الدالة الثابتة في المقابلة

لمجموعة الثانية المحاور. ركز الطلبـة في هذه المجمموعة على محور السينات و الصادات

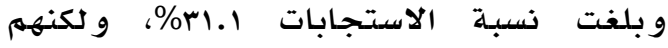

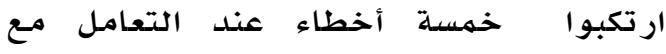

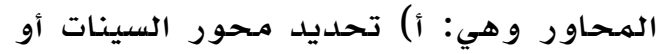

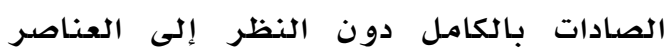

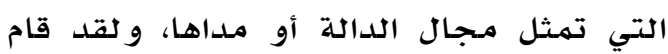

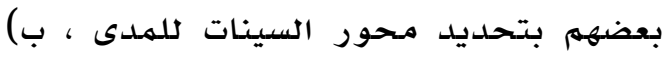

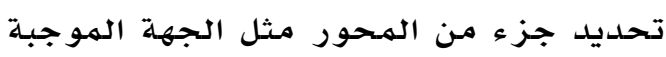

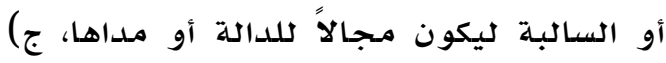
تحديد المحور بفترة مغلقة وتجاهل إثـارة السهم (†) ويضع بـدل منها نقطة وهذا يدل

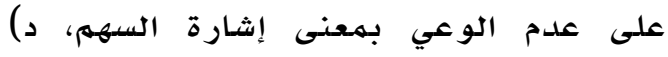
تحديد نقاط على أحد المـحورين للمهجال

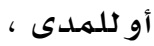

و لقد قام بعض الطلبـة بتحديد المدى بنقاط

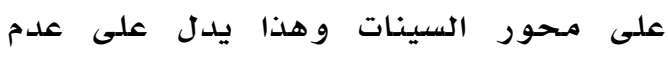
الوعي بـمعنى المدلى و المجال، و تحديد نقاط

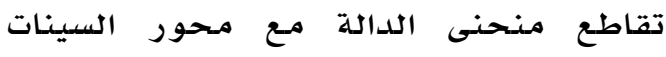

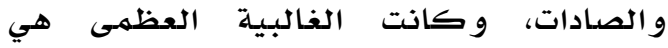




\begin{tabular}{|c|c|c|c|c|c|c|c|c|c|}
\hline \multicolumn{10}{|c|}{ جدول 1} \\
\hline \multirow[t]{2}{*}{ النسبة } & \multicolumn{2}{|c|}{ غير منصلة } & \multicolumn{2}{|c|}{ مثلثية } & \multicolumn{2}{|c|}{ متعددة } & \multicolumn{2}{|c|}{ كثيرات الحدود } & \multirow[t]{2}{*}{ مجموعات استجابات الطلبة } \\
\hline & 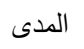 & 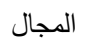 & 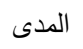 & 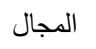 & 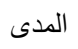 & 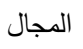 & 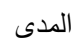 & 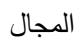 & \\
\hline \multirow[t]{10}{*}{$\% 11$} & . & r & $r$ & $\checkmark$ & r & r & ir & $\checkmark$ & صحيحة \\
\hline & & & & & & & & & المحاور \\
\hline & 1 & v & - & - & r & r & r & $\varepsilon$ & المحور كامل \\
\hline & r & - & $\varepsilon$ & - & 1 & - & r & - & س \\
\hline & & & & & & & & & ص \\
\hline & & & & & & & & & ب) جزء من المحور \\
\hline & - & r & $\varepsilon$ & r & - & 1 & - & - & 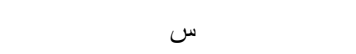 \\
\hline & - & - & - & - & 1 & - & $r$ & - & ص ص n la la \\
\hline & & & & & & & & & ج)تحويل المحور إلى فترة مغلقة \\
\hline & $\varepsilon$ & r & r & $v$ & - & v & - & 1 & 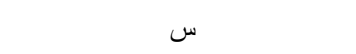 \\
\hline \multirow[t]{9}{*}{$\%+1.1$} & r & - & - & - & 。 & - & - & - & ص ص la la \\
\hline & & & & & & & & & د) نقاط على محور \\
\hline & $\circ$ & 1 & r & - & - & 1 & 1 & - & س - \\
\hline & $\varepsilon$ & - & 1 & - & - & - & - & - & 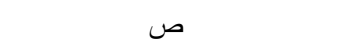 \\
\hline & & & & & & & & & و) نقاطع نقاطع المنحنى مع \\
\hline & - & - & r & - & 1 & 1 & - & - & 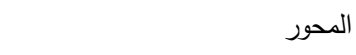 \\
\hline & - & - & 1 & - & 1 & - & - & - & 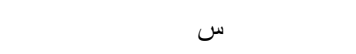 \\
\hline & & & & & & & & & r ) المنحنى ص \\
\hline & - & 10 & 1 & ir & 1 & 17 & r & iv & (') منحنى كامل \\
\hline \multirow[t]{4}{*}{$\%$ \%. 1} & $\circ$ & r & 1 & 1 & r & r & r & r & ب) جزء من المنحنى \\
\hline & 1 & - & - & r & 1 & r & 1 & $\varepsilon$ & ج) منحنى ولكن أغلق وجعل \\
\hline & & & & & & & & & منتهى \\
\hline & - & 1 & r & r & 9 & 1 & 0 & 1 & د) نقاط على المنحنى \\
\hline$\% r . r$ & 1 & - & r & r & 1 & 1 & r & r & مساحات \\
\hline$\% 1 . r$ & $\varepsilon$ & & - & & - & & - & & لا يوجد مدى \\
\hline$\% \backslash \wedge . r$ & ir & v & 11 & 0 & 9 & $\varepsilon$ & 9 & $r$ & لا أعلم \\
\hline$\% 1 \ldots$ & \&1 & $\varepsilon 1$ & $\varepsilon 1$ & $\varepsilon 1$ & $\varepsilon 1$ & $\varepsilon 1$ & $\varepsilon 1$ & $\varepsilon 1$ & المجموع \\
\hline
\end{tabular}

\section{مناقشة النتائج}

لمتوسط الدرجات \%YO,V\%، أي حصل الطلبة

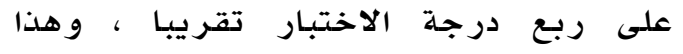

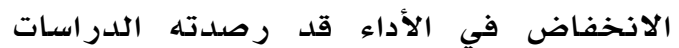

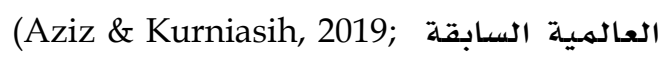
Cho \& Moore-Russo, 2014; Cho, Norris \& Moore-Russo,2017; Özkan \& Ünal, 2009)

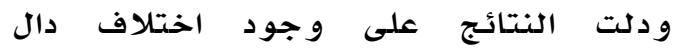
إحصائياً بين أداء الطلبة في تحدئ الهديد المجرال

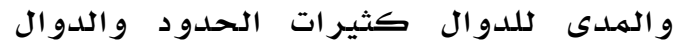
الأخرى: متعددة التعر يف و المثلثية.
إن التمثيل البيانى يعطى صورة للدالة يمكن

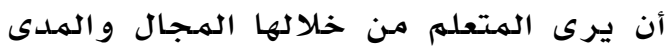

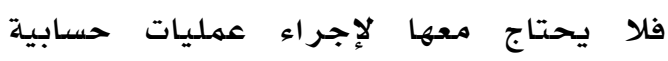

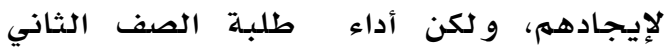

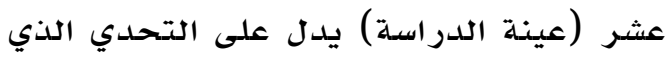

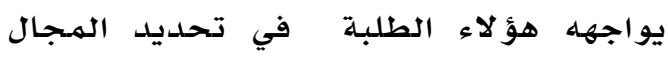

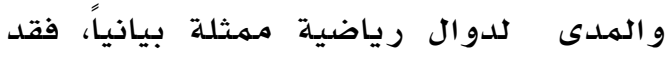

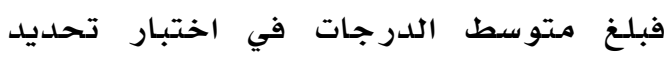

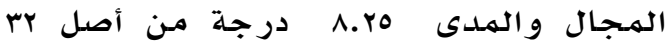
درجة للاختبـار، و بلغت النسبة الهؤية 
الطلبة هذا الاعتقاد الخاطئ ، ووهذا الخطأ يتفق مـع ما كتبـه الباحثان مدلي ور امبرسيد (Mudaly \& Rampersad, 2010)

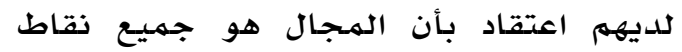
محور السينات و المدى هو جميع نقاط مـحور الصدادات.

و مجمهوعة أخرى عرفت الهـال على أنه

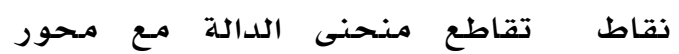

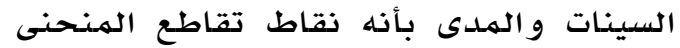

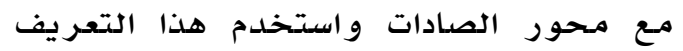
عند تحديد المجال و المدى للدو ال. و أيضا ركز الطلبـة على بعض النقاط على المحاور

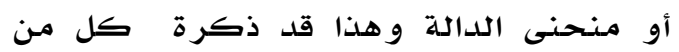

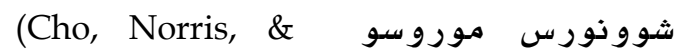

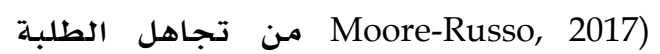

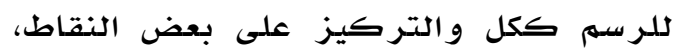

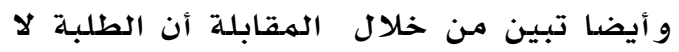

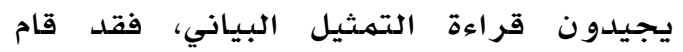
الكثير منهم بتحديد منحنى الدالة وهو نقاط اقتران عناصر الهـال بـالمدى ليكون

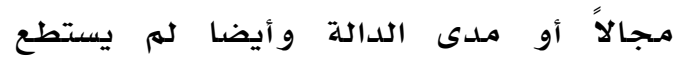

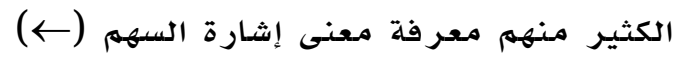

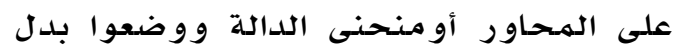
منها نقطة وهذا الضعف في قرأت التمثيل (Cho, البياني يتفق مـ الدراسات السابقة .Norris \& Moore-Russo, 2017)

اعتبر بعض الطلبـة أن المدى غير موجود في

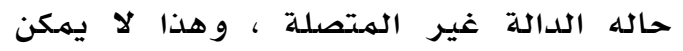
حيث أن المدى من عناصر الدالة الأساسيلة، و لا يوجد دالة من غير مدىى ، وانكار وجود

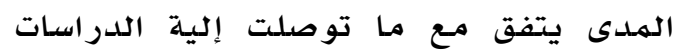
(Cho \& Moore-Russo; 2014) الطلبـة في حال عدم معر فتهم للمدلى ينكرون

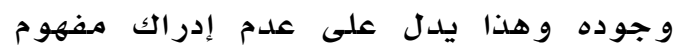
الدالة لدى الطلبة، و أيضا مجهمو عة كبيرة

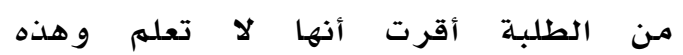

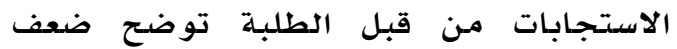
شديد في مفهوم الدالة والتعامل مـع التمثيل البياني.
و غير المتصلة لصالح الدوال كثيرات الحدود، وربما يعود هذا الاختلاف إلى أن أن الدوال كثيرات الحدود تُدرس قبل الدودال

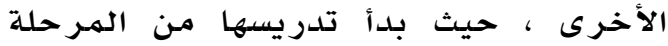
الهـتوسطة ، و بذلك فقد تكون لدى الطلبـة

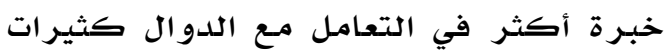

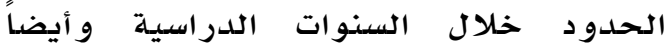
أوضحت النتائج وجود اختلاف دال إحصائياً بين أداء الطلبـة في تحديد الهـجال والمـدى

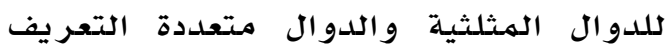

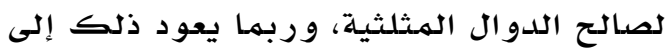

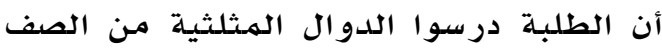

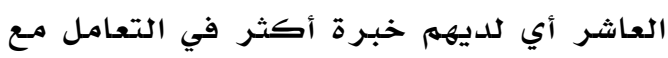
هذا النوع من الدوال. و ولقد و اجه الطلبـة في

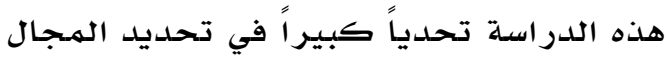
و المدى للدوال متعددة التعريف ، فقد كان متوسط أدائهم في البنود الخخاصدة بالدوال

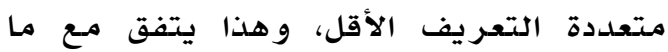
أوضحته الدراسات السابقة من صعوبة هذا

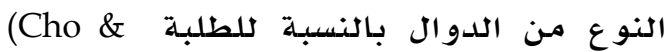
.Moore-Russo; 2014)

تبين نتائج اختبارات دلالة الفروق وجود

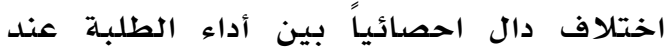
تحديد المجال وعند تحديد المدلى لصالح المجال، وهذا يتفق مـع ما توصل إلية كل من شوو موروسو في درواستهما أن إيجاد الهدى أصعب على الطلبـة من إيجاد الهـال (Cho \& Moore-Russo; 2014; Van Dyke \& (White, 2004) الكتب الملدرسية على إيجاد الهجال أكثر من المدلى. تبين من خلال نتائج المقابلات ضعف مقدرة

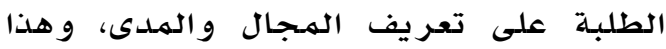
الضعف في المقدرة على التعريف يتفق مـع ما توصلت عليه دراسـة عزيز وركرنيش ،(Abdullah, 2010; Aziz, \& Kurniasih, 2019) و لقد عرف مجمموعة مـن الطلبة المجال بأنه محور السينات كاملاً و ومحور الصدادات

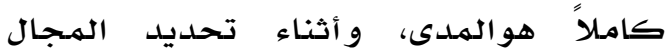

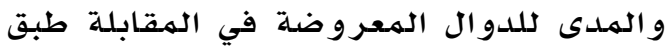




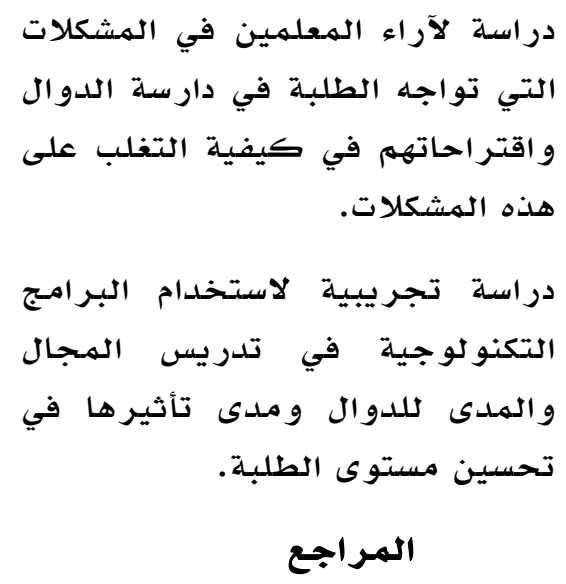
rvirvavaspx?id=

النذير، محمد بن عبدالله بن عثمان، (10) (r). مستوى تمكن الطلاب المستتجدين

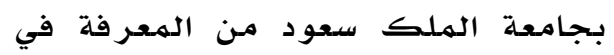
الرياضيات الجأساسية

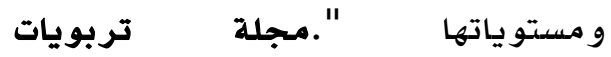
الرياضيات: الجمعية المصرية لتربويات

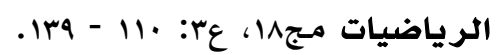

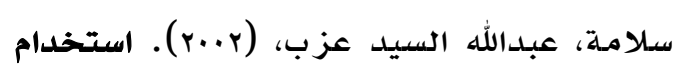
المدخل البصري في تلدريس الدوال

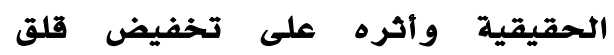

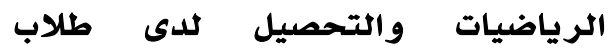
التعليم الثانوي القسم العلمي: دراسة تجريبية. في المؤتهر العلهي السنوي

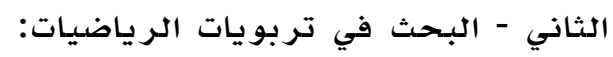

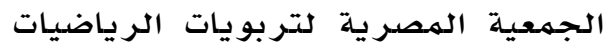

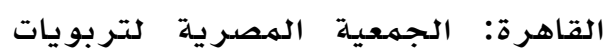

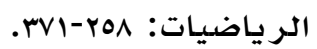
محمد، إيهاب السيد شحاتة، (عاتب). "تصور

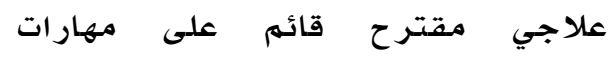
التواصل الرياضي لعلاج صعوبات تعلهم

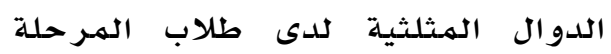

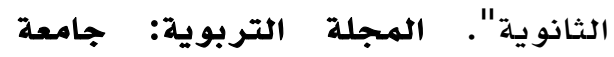
سوهاج - كلية التربية. ج؟r: هץ - r.1.

\section{التو صيات}

نتائج الدراسـة تدل على تدني مستوى الطلبـة

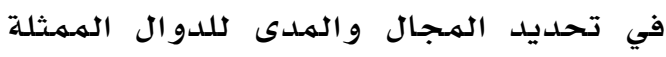
بيانيا، لذلك تتضمن التوصيات محورين الأول يركز على تدريس المـجال والمـدى

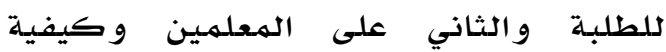
تدريس المجال والمدى للدوال الممثللة بيانيا المحور الأول: على معلمي وموجي

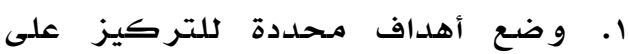

عناصر الدالة أثناء التدريس مثل ملده

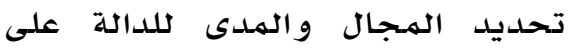

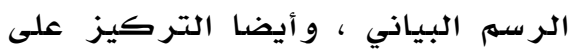

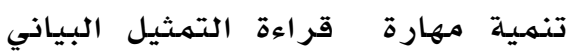

لدى الطلبة ووضع أهداف محلددة لهارة مثل قراءة التهثيل البياني.

r. يجب أن تتضمن اختبارات الرياضيات

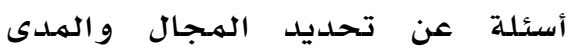

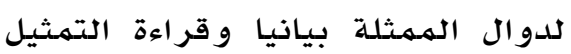

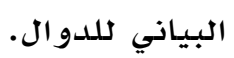

المحور الثاني: يتعلق بالمعلمين أهناء

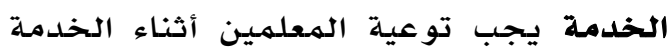

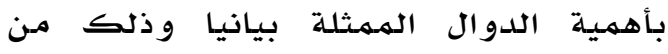

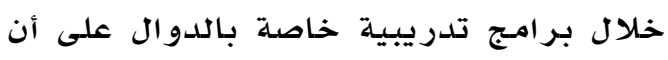
تركز هذه البرامج على أهميلة تلدريب

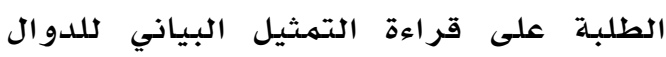

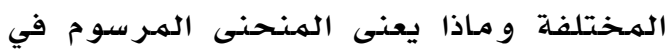

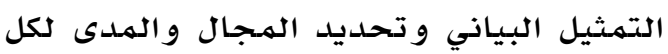

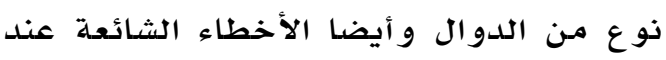
الطلبة في تحديد المجال و المدلى للدوال

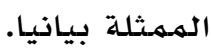

\section{دراسات مستقبلية}

دراسـة مدى معرفة طلبـة المـرحلة

الثاذوية المدلى والمجال للتمثيلات

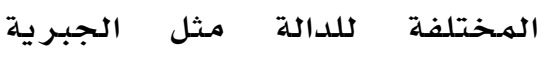

و الجدو لية و المخططات السهمية.

دراسـة تحليلية لكيفية عرض كتب

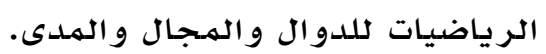


Abdullah, S. A. S. (2010). Comprehending the concept of functions. ProcediaSocial and Behavioral Sciences, 8, 281-287.

Aziz, T. A., \& Kurniasih, M. D. (2019). External Representation Flexibility of Domain and Range of Function. Journal on Mathematics Education, 10(1), 143-156.

Berg, C. A., \& Smith, P. (1994). Assessing students' abilities to construct and interpret line graphs: Disparities between multiple-choice and freeresponse instruments. Science Education, 78(6), 527-554.

Bittinger, M. L., Ellenbogen, D. J., \& Johnson, B. L. (2010). Elementary and intermediate algebra: graphs and models (4th ed.). Boston: Addison Wesley.

Carlson, M., \& Oehrtman, M. (2005). Key aspects of knowing and learning the concept of function. Research Sampler Series, 9, The Mathematical Association of America Notes Online. http://www.maa.org/t_and_l/sampl er/rs_9.html

Cho, Y. D. (2013). College Students' Understanding of the Domain and Range of Functions on Graphs. Buffalo: State University of New York at Buffalo.

Cho, P., \& Moore-Russo, D. (2014). How students come to understand the domain and range for the graphs of functions. Proceedings of the Joint Meeting of the PME 38 and PME-NA 36 (Vol. 2, pp. 281-288). Vancouver: International Group for the Psychology of Mathematics Education.

Cho, P., Norris, B., \& Moore-Russo, D. (2017). A study of common student practices for determining the domain and range of graphs. Investigations in Mathematics Learning, 9(4), 202-219.

Dubinsky, E., \& Wilson, R. T. (2013). High school students' understanding of the function concept. The Journal of Mathematical Behavior, 32(1), 83-101.
Eisenberg, T. (1992). On the development of a sense for functions. In $\mathrm{E}$. Dubinsky \& G. Harel (Eds.), The concept of function. Aspects of epistemology and pedagogy (pp. 153174). The Mathematical Association of America.

Even, R. (1998). Factors involved in linking representations of functions. The Journal of Mathematical Behavior, 17(1), 105-121.

Herman, M. (2007). What students choose to do and have to say about use of multiple representations in college algebra. Journal of Computers in Mathematics and Science Teaching, 26(1), 27-54.

Kalchman, M., \& Case, R. (1998). Teaching mathematical functions in primary and middle school: An approach based on neo-Piagetian theory. Sciatica pedagogical experimentalism, 35(1), 7-54.

Knuth, E. J. (2000a). Understanding connections between equations and graphs. The Mathematics Teacher, 93(1), 48-53.

Knuth, E. J. (2000b). Student understanding of the Cartesian Connection: An exploratory study. Journal of Research in Mathematics Education, 31(4), 500-508.

Leinhardt, G., Zaslavsky, O., \& Stein, M. K. (1990). Functions, graphs, and graphing: Tasks, learning, and teaching. Review of educational research, 60(1), 1-64.

Mudaly, V., \& Rampersad, R. (2010). The role of visualization in learners' conceptual understanding of graphical functional relationships. African Journal of Research in Mathematics, Science and Technology Education, 14(1), 36-48.

National Council of Teachers of Mathematics. (2000). Principles and standards for school mathematics. Reston, VA: Author.

Özkan, E. M., \& Ünal, H. (2009). Misconception in Calculus-I: Engineering students' misconceptions 
in the process of finding domain of functions. Procedia-Social and Behavioral Sciences, 1(1), 1792-1796.

Pesek, D. D., \& Kirshner, D. (2000). Interference of instrumental instruction in subsequent relational learning. Journal for Research in Mathematics Education 31(5), 524-540.

Selden, A., \& Selden, J. (1992). Research perspectives on conceptions of function: Summary and overview. In G. Harel \& E. Dubinsky (Eds.), The concept of function: Aspects of epistemology and pedagogy (pp. 1-16). Washington, DC: Mathematical Association of America.

Tall, D. \& Bakar, M. (1991). Students' mental prototypes for functions and graphs. In Proceedings of

the conference of the international group for the psychology of mathematics education (pp. 104-111). Assisi: PME.

Van Dyke, F. \& White, A. (2004). Examining students' reluctance to use graphs. The Mathematics Teacher, 98(2), 110-117. 